\title{
Astronomische
} Nachrichten.

\author{
Expedition auf der Königlichen Sternwarte bei Kiel. \\ Ferausgeber: Prof: Dr. C. A. F. Peters.
}

Band 89.

Nr. 2124

\section{Beobachtungen der Sonnenflecken und Protuberanzen im Jahre 1876.}

(Schluss.)

Demnach müsste 1877 folgen mit einer mittleren Breite von etwa $9^{\circ}$ wie im Jahre 1866 , oder mit weniger als $9^{0}$ wie im Jahre 1855; und wir hätten beide Male Perioden von 11 Jahren. Die Erscheinung eines zahlreicheren Fleckenzuges in hohen Breiten, welche in den Jahren 1856 und 1867 beobachtet wurde, wäre mithin erst im Jahre 1878 zu erwarten.

Als Vorlaufer hierzu sind die beiden kleinen Flecke No. 18 und No. 36 bezeichnet, aber im Jahre 1876 fehlten noch die kleinen ovalen Fackelstellen, welche im Jahre 1866 haufiger in den Polargegenden beobachtet wurden. Anderweitig ist eine Andeutung zu finden, dass von hohen Breiten her besonderes bevorsteht, nämlich das Verhalten der Chromosphäre an den Polen. An manchen Tagen d. J. 1876 war die Chromosphare an weiten Strecken des Sonnenrandes überaus niedrig, besonders Mai 18. und 19. Nor. 4. etc., dagegen an den Polen und in der Nähe derselben war die Chromosphäre häufig auffallend hoch, so dass man die Erböhung als eine fortlaufende Kette müssiger Protuberanzen bezeichnen konnte, z. B. Aug. 17. am Südpol und Nordpol, Aug. 19. am Nordpol, Sept. 5 bis 14 am Südpol, Sept. 14, 2:1, und Oct. 6 und 9 am Nordpol, Oct. 9 und 11 am Südpol. Wiederholt hat schon $P$ Sccchi dirauf aufmerksam gemacht.

Im Allgemeinen war im Jahre 1876 die Beobachtung der Protuberanzen wenig lohnend, weil zugleich mit der Abnahme der Flecke auch eine Abnahme der Protuberanzen eingetreten ist. Die flammigen Protuberanzen erlangten nicht so ausgezeichneto Formen wie zur Zeit des Flecken-Maximum's, und ihre Spitzen überragten oft die Chromosphare nur wenig oder gar nicht. Daher liessen sich auch nur selten die sonst beobachteten schnellen Aenderungen dieser Protuberanzen bemerken. Ein Beispiel mag vom 14. April angeführt werden, an welches wir anderes anknïpfen. Eine Bd. 89. kleine helle Stelle wurde $8^{\text {h }} 40^{\mathrm{m}}$ am Westrande gefunden; hieraus erhob sich $8^{\mathrm{h}} 5^{5} 8^{\mathrm{m}}$ ein hoher intensiv leuchtender Strahl, der in mehrere Spitzen auslief. Dieser war $9^{\mathrm{h}} 3^{\mathrm{m}}$ weniger bedeutend, und $9^{\mathrm{h}} 5^{\mathrm{m}}$ hörte das starke Leuchten auf. Weiter nördlich von dieser Stelle befand sich eine lockere Wolke, und diese grenzte genau südlich an den Ort des Flecks No. 18. Auch für den anderen in hoher Breite $\left(+43^{\circ}\right)$ beobachteten Fleck No. 36 lusst sich eine benachbarte Protuberanz nachweisen, nämlich Sept. 14. gerade nördlich in $47^{\circ}$ Breite ein aufstrebendes Gebilde, welches keine Verbindung mit der Chromosphäre hatte. Weiter nördlich bei $\mathrm{b}=$ $+55^{\circ}$ befand sich eine ansehnliche Wasserstoff-Protuberanz mit breiter Basis, und diese war die üstliche Fortsetzung einer Protuberanz, die mit schmaler Basis Sept. 13. beobachtet wurde. Letztere ist von Interesse dadurch, dass sie sich den Fallen anreiht, welche ich mit unseren Tromben verglichen habe. Indem bei dieser Protuberanz (Sept. 13) eine obere wolkenartige Ausbreitung stattfand, senkte sich um $9^{\mathrm{h}}$ ein nördlicher Zweig herab, welchem genau entsprechend von der Sonnenoberfläche cine aufstrebende mässige Protuberanz entgegenkam, so dass sich die beiderseitigen Spitzen fast berihhrten, und um $9^{\mathrm{h}} 3^{\mathrm{m}}$ trat derselbe Fall auch südlich ein. An beiden Stellen waren die von der Oberfliche entgegenkommenden Erhöhungen auffallend heller, als die oberen herabgesenkten Theile.

Wiederholt ist von den Wasserstoffprotuberanzen die Breite $50^{\circ}$ überschritten, aber selten die Breite ron $60^{\circ}$. Mit Berücksichtigung der vielen kleinen Protuberanzen kam die Mehrzahl in den Aequatorial-Zonen zwischen $+30^{\circ}$ und $-30^{\circ}$ Breite vor.

Potsdam 1877 Febr. 16. Prof. Spoerer. 